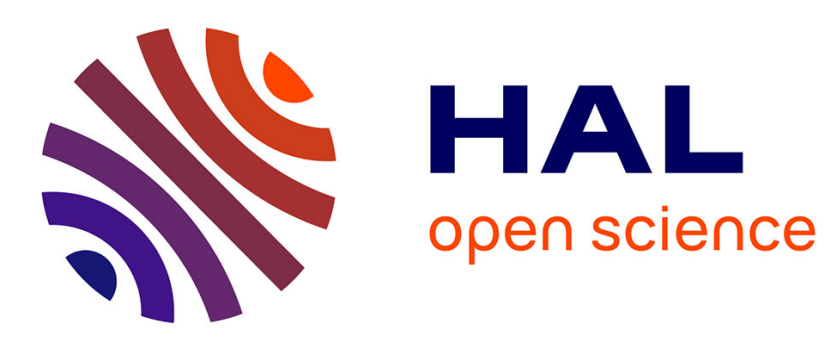

\title{
Stability of the D-OSKIL Oscillation Suppression Mechanism for Oil Well Drillstrings
}

Miguel Corchero, Carlos Canudas de Wit, Francisco Rubio

\section{To cite this version:}

Miguel Corchero, Carlos Canudas de Wit, Francisco Rubio. Stability of the D-OSKIL Oscillation Suppression Mechanism for Oil Well Drillstrings. 45th IEEE Conference on Decision and Control, CDC 2006, Dec 2006, -, France. pp.6. hal-00130857

\section{HAL Id: hal-00130857 https://hal.science/hal-00130857}

Submitted on 14 Feb 2007

HAL is a multi-disciplinary open access archive for the deposit and dissemination of scientific research documents, whether they are published or not. The documents may come from teaching and research institutions in France or abroad, or from public or private research centers.
L'archive ouverte pluridisciplinaire HAL, est destinée au dépôt et à la diffusion de documents scientifiques de niveau recherche, publiés ou non, émanant des établissements d'enseignement et de recherche français ou étrangers, des laboratoires publics ou privés. 


\title{
Stability of the D-OSKIL Oscillation Suppression Mechanism for Oil Well Drillstrings
}

\author{
Miguel A. Corchero, Carlos Canudas-de-Wit and Francisco R. Rubio .
}

\begin{abstract}
The presence of harmful stick-slip oscillations in oil well drillstrings has attracted the attention of the control community in recent years. In this paper, we present stability proofs for new Weight on Bit $\left(W_{o B}\right)$ control law of the type introduced in [3]. We show that the resulting feedback system of the proposed law is globally asymptotically stable. Simulations showing the typical response profiles obtained from the control algorithm designed are also presented.
\end{abstract}

Index Terms-Stick-Slip, Oil Well Drillstring, D-OSKIL control, Passivity, Lyapunov stability.

\section{INTRODUCTION}

Drillstring systems are used by the oil industry to extract gas and oil from earth surface. Using a rotatory device, a hole is made on the surface of the earth crushing the rock formation. An exhaustive description of the process and the system can be found in [10].

The occurrence of self-excited stick-slip vibrations as a common and damaging phenomena in drillstring systems has been exhaustively described and analyzed in last years, attracting the attention of the control community (see [6], [12], [17]). Among some other causes, these oscillations are mainly due to the important friction torque produced by the contact between the cutting device and the rock formation [9].

The reduction and avoidance of such oscillations has been proved to be very valuable in terms on money and exploitation time [10].

Many ways of reducing these vibrations have been proposed in literature, for instance, by manipulating some drilling parameters (for example, [13] and [15]), by modifying the design of the drilling device (for example, [5] and [14]), or by introducing a specific controller to avoid oscillations (for example [4], [7], [16]).

However, few works have provided formal stability analysis of their proposed control strategies. For instance, analysis of the dynamical behavior of drillstring under vibrations has been explored in [1] and linear approximations to stability of controlled drillstring has been studied in [12].

The value of the system weight measured at the bottom part, called Weight on Bit $\left(W_{o B}\right)$, has been proved to be an important parameter in the occurrence and possible avoidance of stick-slip oscillations (see [11] and [15]).

C. Canudas-de-Wit is with the Laboratoire d'Automatique de Grenoble, UMR CNRS 5528, ENSIEG-INPG, B.P. 46, 38 402, ST. Martin d'Hères, FRANCE. Email: carlos.canudas-de-witeinpg.fr.

Miguel A. Corchero and Francisco R. Rubio are with the Escuela Técnica Superior de Ingenieros, University of Seville, Camino de los Descubrimientos s/n, 41092-Sevilla, SPAIN. Email: macperu@us.es, rubio@esi.us.es.
The necessity of a high value of the $W_{O B}$ to carry out a good performance drilling task and the fact that the possibility of stick-slip occurrence is lower for low values of $W_{O B}$ means that the introduction of a regulation strategy of $W_{O B}$ value seems to be proper to maintain a good drilling operation, and so, avoiding such oscillations (see [3] and [12]).

Although these control algorithms have been shown to work properly in simulation, and some analysis have been carried out through approximated methods (such as the describing function analysis), stability studies fully supporting the validity of such techniques are still missing. In this paper, we present a formal stability approach to $W_{O B}$ controller design presented in [3].

In Section II, the basic ideas of the stick-slip oscillation avoidance problem are recalled. In Section III, a new control strategy and its stability analysis is presented. In Section IV, simulations are shown, and finally, Section V presents the conclusions.

\section{MOdEL AND PROBLEM FORMULATION}

Figure 1 depicts a diagram describing a commonly used simplified model of drillstring torsional dynamics. The equations describing this model are:

$$
\begin{aligned}
J_{r} \ddot{\varphi}_{r}+c\left(\dot{\varphi}_{r}-\dot{\varphi}_{b}\right)+k\left(\varphi_{r}-\varphi_{b}\right)+d_{r} \dot{\varphi}_{r} & =v \\
J_{b} \ddot{\varphi}_{b}+c\left(\dot{\varphi}_{b}-\dot{\varphi}_{r}\right)+k\left(\varphi_{b}-\varphi_{r}\right)+d_{b} \dot{\varphi}_{b} & =-T_{o B}
\end{aligned}
$$

where $v$ is the control signal over the motor which moves the rotatory, and the $T_{o B}$ is given by the product of $\mu\left(\dot{\varphi}_{b}\right)$, which describes the normalized dimensionless torsional bitrock friction, and the normal force $u$ usually called Weight on Bit $\left(W_{O B}\right)$, which is the sum of the nominal weight of the drillstring $\left(u_{0}\right)$ and the D-OSKIL control signal $(\tilde{u})$ :

$$
T_{o B}=\mu\left(\dot{\varphi}_{b}\right) \cdot u, \quad u=u_{0}+\tilde{u}
$$

The control variables are supposed to have the following structure. First, the variable $v$ will take the form:

$$
v=\left[k_{1}+\frac{k_{2}}{s}\right]\left(\omega_{d}-\dot{\varphi}_{r}\right)-k_{3}\left(\dot{\varphi}_{r}-\dot{\varphi}_{b}\right)
$$

whose gains $k_{1}, k_{2}$ and $k_{3}$ have been computed following a classic two-time-scales separation method. And secondly, the control variable over $W_{o B}$ follows the adaptation law given by:

$$
\dot{\tilde{u}}=\mathcal{P}_{-u_{0}}^{0}\{-\sigma \tilde{u}+\Phi(\cdot)\}
$$

where $\mathcal{P}_{-u_{0}}^{0}$ is a projector operator ensuring that solutions of the above equation makes $\tilde{u}$ stay in the range $\left(-u_{0}, 0\right]$, 

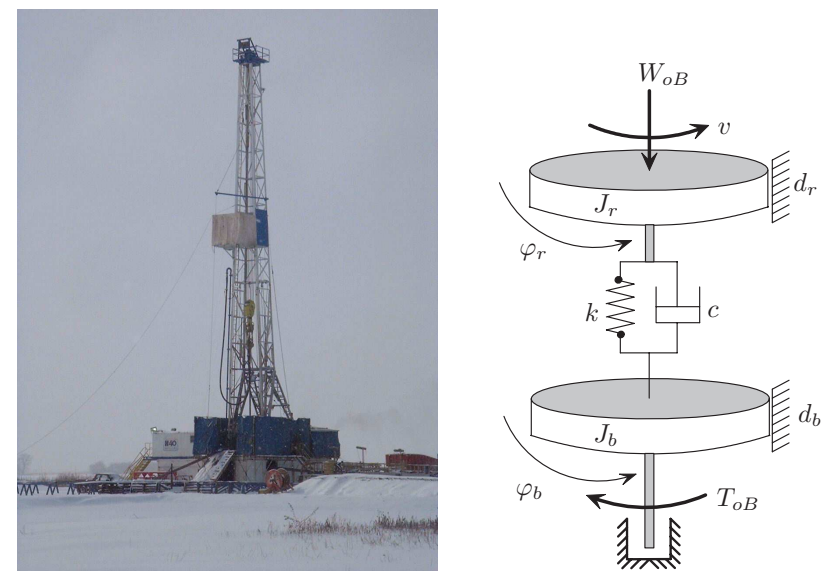

Fig. 1. Drillstring view and two-coupled masses model.

and $\Phi(\cdot)$ is a nonlinear function which must be designed to ensure system stability, that is:

$$
\dot{\varphi}_{r} \rightarrow \omega_{d} \quad \text { and } \quad \tilde{u} \rightarrow 0
$$

In order to make the presentation simpler, we will trop in the sequel the explicit use of the projection operation $\mathcal{P}$. However, reader should keep in mind that $\tilde{u}$ is a bounded signals in the prescribed range.

\section{A. State-space model}

Under these assumptions, the system in state-space form can be presented as follows:

$$
\begin{gathered}
\dot{x}=A_{c l} x+B_{c l} \omega_{d}+H_{c l} \mu\left(x_{3}\right)\left(u_{0}+\tilde{u}\right) \\
\dot{\tilde{u}}=-\sigma \tilde{u}+\Phi(\cdot) \\
A_{c l}=\left(\begin{array}{cccc}
0 & 1 & -1 & 0 \\
\frac{-k}{J_{r}} & \frac{-\left(d_{r}+c+k_{1}+k_{3}\right)}{J_{r}} & \frac{\left(c+k_{3}\right)}{J_{r}} & \frac{k_{2}}{J_{r}} \\
\frac{k}{J_{b}} & \frac{c}{J_{b}} & \frac{-\left(c+d_{b}\right)}{J_{b}} & 0 \\
0 & -1 & 0 & 0
\end{array}\right) \\
B_{c l}=\left[\begin{array}{llll}
0 & \frac{k_{1}}{J_{r}} & 0 & 1
\end{array}\right]^{T} \\
H_{c l}=\left[\begin{array}{llll}
0 & 0 & \frac{-1}{J_{b}} & 0
\end{array}\right]^{T}
\end{gathered}
$$

with:

$$
\begin{aligned}
x_{1} & =\varphi_{r}-\varphi_{b} \\
x_{2} & =\dot{\varphi}_{r} \\
x_{3} & =\dot{\varphi}_{b} \\
x_{4} & =\int_{0}^{t} \omega_{d} d t-\varphi_{r}
\end{aligned}
$$

The steady-state values of the states, considering $\mu^{*}=\mu\left(x_{3}^{*}\right)$, are the following:

$$
\begin{aligned}
x_{1}^{*} & =\frac{u_{0} \mu^{*}+d_{b} \omega_{d}}{k} \\
x_{2}^{*} & =\omega_{d} \\
x_{3}^{*} & =\omega_{d} \\
x_{4}^{*} & =\frac{\left(d_{b}+d_{r}\right) \omega_{d}+\mu^{*} u_{0}}{k_{2}}
\end{aligned}
$$

Therefore, rotatory table and bit velocities stabilize at the desired rotational velocity, which reveals a proper feature in our feedback control law.

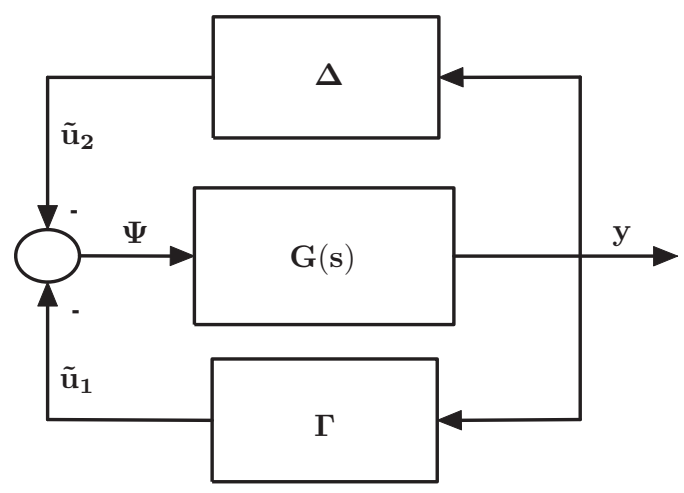

Fig. 2. Error system block diagram.

\section{B. Error equations}

Error equations can be obtained by applying the change of coordinates $e=x-x^{*}$, and considering the steady-state values $\mu\left(e_{3}\right)_{s s}=\mu^{*}$ and $\tilde{u}_{s s}=0$. This yields ${ }^{1}$ :

$$
\begin{aligned}
\dot{e} & =A_{c l} e+H_{c l}\left[\mu(y) \tilde{u}+\tilde{\mu}(y) u_{0}\right] \\
\dot{\tilde{u}} & =-\sigma \tilde{u}+\Phi(y) \\
y & =C e=e_{3}
\end{aligned}
$$

where the term $\tilde{\mu}(y)$ is defined as follows:

$$
\tilde{\mu}(y)=\mu(y)-\mu^{*}
$$

and we assume that the update rule for $\tilde{u}$ is designed on the basis of the output $y$. The error system can be described by the block diagram in Figure 2, with the following definitions:

$$
\begin{aligned}
& G(s): \quad \Psi \mapsto y \\
& \Gamma \quad: \quad y \mapsto \tilde{u}_{1}=\mu(y) \tilde{u} \\
& \Delta \quad: \quad y \mapsto \tilde{u}_{2}=\tilde{\mu}(y) u_{0}
\end{aligned}
$$

where $\Psi=-\left(\tilde{u}_{1}+\tilde{u}_{2}\right)$.

\section{Error equation properties}

1) PR condition on $G(s)$ : The map $G(s)$ is:

$$
G(s)=-C\left(s I-A_{c l}\right) H_{c l}
$$

with $C=\left[\begin{array}{llll}0 & 0 & 1 & 0\end{array}\right]$, or equivalently:

$$
G(s)=\frac{s\left(a_{2} s^{2}+a_{1} s+a_{0}\right)}{b_{4} s^{4}+b_{3} s^{3}+b_{2} s^{2}+b_{1} s+b_{0}}
$$

The error equation and updating rule of $\tilde{u}$ have been designed such that the resulting map $G(s)$ has relative degree one. This condition is necessary to obtain PR and SPR functions. For typical values of drillstring system model parameters and $v$-control gains, it is possible to show that $G(s)$ is a

\footnotetext{
${ }^{1}$ With an abuse of notation, we will use $\mu(y)$ to denote the expression of $\mu\left(x_{3}\right)$, in the shift coordinate $y+\omega_{d}$, i.e. $\mu\left(x_{3}\right)=\mu\left(y+\omega_{d}\right)=\mu(y)$. Note that at $y=0$, we have $\mu(y=0)=\mu\left(\omega_{d}\right)=\mu^{*}$.
} 
Positive Real (PR) function. Consequently, from the KalmanYacubovich-Popov Lemma [8], the following property holds: $\exists P=P^{T},>0, Q=L^{T} L \geq 0$ such that:

$$
\begin{aligned}
A_{c l}^{T} P+P A_{c l} & =-Q=-L^{T} L \leq 0 \\
P H_{c l} & =-C
\end{aligned}
$$

Therefore, as a consequence we have the following two properties for the linear map $G(s)$ :

- $G(s)$ is passive relative to $V(e)=e^{T} P e$, and

- $G(s)$ has finite $L_{2}$-gain: $\gamma_{2}(G)=\sup _{\omega}|G(j \omega)|<\infty$

2) Boundedness of signal $\Psi(t)$ : From the definitions of $\tilde{u}_{1}$ and $\tilde{u}_{2}$ in Equations (14) and (15), together with the assumption that the adaptation mechanism yields values in the range $\tilde{u} \in\left(-u_{0}, 0\right]$, it follows that both signals, $\tilde{u}_{1}$ and $\tilde{u}_{2}$, are bounded, that is:

$$
\begin{aligned}
& \left\|\tilde{u}_{1}\right\|_{\infty}=\sup _{t \geq 0}\left|\tilde{u}_{1}\right| \leq u_{0}<\infty, \\
& \left\|\tilde{u}_{2}\right\|_{\infty}=\sup _{t \geq 0}\left|\tilde{u}_{2}\right| \leq 2 \cdot u_{0}<\infty .
\end{aligned}
$$

Hence $\|\Psi(t)\|_{\infty} \leq 3 \cdot u_{0}$.

3) Boundedness of the output $y(t)$ : Since $G(s): \Psi \mapsto y$ is a lineal stable map, the output signal $y$ is also bounded, i.e.

$$
\Psi \in L_{\infty} \Rightarrow y \in L_{\infty}
$$

4) Sector condition on $\Delta$ : With regard to the Figure 2, the output of the map $\Delta$ can be seen as a disturbance acting on the closed loop system resulting from the operators $G(s)$ in feedback connection with nonlinear operator $\Gamma$.

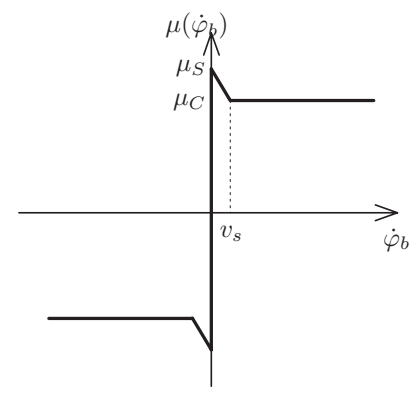

Fig. 3. Normalized friction function.

Figure 3 shows the memoryless friction map used for this study. Note that as the steady-state rotatory bit speed $\left(\omega_{d}\right)$ is in general much bigger than the Stribeck velocity $v_{s}$, we can then assume that $\mu^{*}=\mu_{C}$. Therefore, taking into account that $y=e_{3}=\dot{\varphi}_{b}-\omega_{d}$, the output of block $\Delta$ will have the profile shown in Figure 4. This operator belongs to the cone sector $[a, b]$ as displayed in the same Figure (see [18] for further discussion on sector definitions). Formally this is stated as follows.

The nonlinear operator $\Delta(y)$ belong to the sector $[a, b]$ if the following hold:

- $\Delta(0)=0$

- $a \leq \frac{\Delta(y)}{y} \leq b, \forall y \geq 0$, or equivalently,

- $a y^{2} \leq y \Delta(y) \leq b y^{2}, \forall y \in \Re$

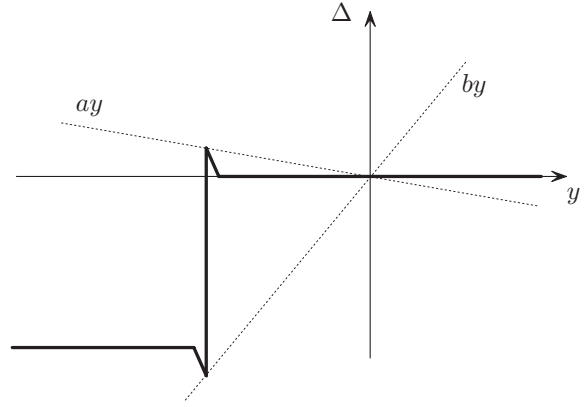

Fig. 4. $\Delta(y)$ belonging to interval $[a, b]$.

In our case, the values for $a$ and $b$ are:

$$
\begin{aligned}
a & =-\frac{\mu_{S}-\mu_{C}}{\omega_{d}} u_{0} \\
b & =\frac{\mu_{S}+\mu_{C}}{\omega_{d}} u_{0}
\end{aligned}
$$

and consequently, the map $\Delta$ has also finite $L_{2}$-gain, which is bounded by:

$$
\gamma_{2}(\Delta) \leq \max [|a|,|b|]
$$

5) Block transformation: As it can be seen in Figure 4, the map $\Delta$ is almost passive, since almost the whole diagram is within the first and third quadrant. This characteristic is generic as the difference between break-away and Coulomb friction levels is in general small ( $a$ is small when compared to $b$ ).

Figure 5 shows a possible block transformation, where the following new operators, $\Delta^{*}$, and $\Gamma^{*}$ are defined:

$$
\begin{array}{ll}
\Delta^{*} & : \quad y \mapsto\left(\tilde{u}_{2}+\varepsilon y\right) \\
\Gamma^{*} & : \quad y \mapsto\left(\tilde{u}_{1}-\varepsilon y\right)
\end{array}
$$

With this transformation, it can be easily proved that the map $\Delta^{*}$ is passive if the value of $\varepsilon$ is taken such that $\varepsilon=|a|$, as can be seen in Figure 6.

$$
\varepsilon=|a| \Rightarrow \int_{0}^{t} y\left(\tilde{u}_{2}+\varepsilon y\right) d t \geq 0
$$

\section{Problem statement}

With this new feedback configuration, the problem of designing a stable update law for $\tilde{u}(t)$ is equivalent of finding a function $\Phi(y)$, and parameter conditions, such that the transformed operator $\Gamma^{*}$ defines a passive map. This design strategy results from well known properties of feedback interconnected passive systems.

The next Section uses such result to demonstrate the stability properties of one possible candidate update rule.

\section{D-OSKIL UPDATING LAW}

Under the premise that the complete form of the update law should also include a suited projection operator ensuring that the variation of $\tilde{u}$ is limited to the admissible parameters range, the following updating rule will be analyzed. 


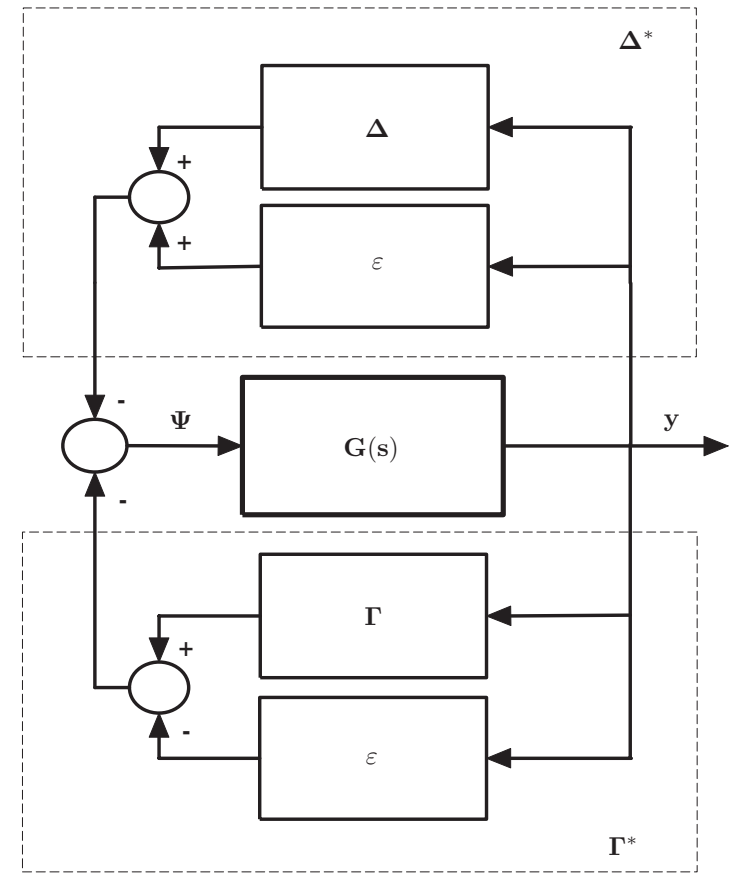

Fig. 5. Modified Block Diagram.

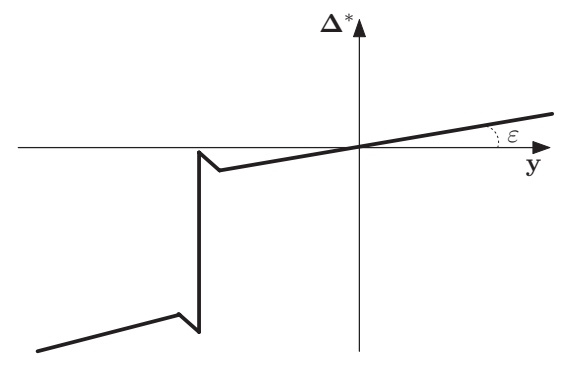

Fig. 6. Profile of map $\Delta^{*}$.

\section{A. Update law}

Let us consider the nonlinear function $\Phi(y)$ :

$$
\Phi(y)=\lambda y \operatorname{sgn}(\mu(y)) \quad \lambda \geq 0
$$

Note that this choice is conditioned to the ability of computing the sign of $\mu(y)$. Considering the form of the friction model for this study, the sign of $\mu(y)=\mu\left(\dot{\varphi}_{b}-\omega_{d}\right)$, can be computed if $\dot{\varphi}_{b}$ can be measured, or at least, observed (see [2] for an example of observer design). We proceed under this hypothesis in what follows.

\section{B. Stability analysis}

Lemma 1: Let $\rho>0$ be an arbitrarily positive constant, and $\lambda, \sigma$ be such that the following design inequality holds,

$$
\frac{\lambda}{\sigma} \geq\left(\frac{\mu_{S}}{\mu_{C}}-1\right) \frac{u_{0}}{\omega_{d}}+\frac{\sigma}{\mu_{C}} \rho
$$

where $\frac{\mu_{S}}{\mu_{C}} \geq 1$. Then map $\Gamma^{*}: y \mapsto(\mu(y) \tilde{u}-\varepsilon y)$ is strictly input passive, i.e.

$$
I=\int_{0}^{t}(\mu(y) \tilde{u}-\varepsilon y) y \geq \rho \int_{0}^{t} y^{2}-\beta_{0}
$$

with $\beta_{0}=\frac{y_{\max }}{\sigma} 2 u_{0}>0$.

Proof: Let $I$ define the integral of the input-output product of the operator $\Gamma^{*}$, i.e.

$$
I=\int_{0}^{t}(\mu(y) \tilde{u}-\varepsilon y) y=\int_{0}^{t} \mu(y) \tilde{u} y-\int_{0}^{t} \varepsilon y^{2}
$$

Substituting $\tilde{u}$ from Equation (10) in the above expression gives,

$$
I=\frac{1}{\sigma} \int_{0}^{t} \mu(y) \Phi(y) y-\frac{1}{\sigma} \int_{0}^{t} \mu(y) y \dot{\tilde{u}}-\int_{0}^{t} \varepsilon y^{2}
$$

From sections II-C.2, and II-C.3, signals $y$ and $\mu(y)$ have been shown to be bounded. Let note these bounds as: $|y|<y_{\max },|\mu(y)|<1$. Therefore,

$$
I \geq \frac{1}{\sigma} \int_{0}^{t} \mu(y) y \Phi(y)-\int_{0}^{t} \varepsilon y^{2}-\frac{y_{\max }}{\sigma}\left|\int_{0}^{t} \dot{\tilde{u}}\right|
$$

Taking now $\Phi(y)=\lambda y \operatorname{sgn}(\mu(y))$, gives

$$
\begin{aligned}
I & \geq \frac{1}{\sigma} \int_{0}^{t}\left(\frac{\lambda}{\sigma}|\mu(y)|-\varepsilon\right) y^{2}-\frac{y_{\max }}{\sigma}|\tilde{u}(t)-\tilde{u}(0)| \\
& \geq \frac{1}{\sigma} \int_{0}^{t}\left(\frac{\lambda}{\sigma}|\mu(y)|-\varepsilon\right) y^{2}-\frac{y_{\max }}{\sigma} 2 u_{0} \\
& \geq \frac{1}{\sigma} \int_{0}^{t}\left(\frac{\lambda}{\sigma} \mu_{C}-|a|\right) y^{2}-\beta_{0}
\end{aligned}
$$

where the last inequality is obtained by using the lower bound on $|\mu(y)|$, i.e., $|\mu(y)| \geq \mu_{C}$, the definition of $\varepsilon=$ $|a|$ (with $a$ as given in Equation (23)) and the constant $\beta_{0}=\frac{y_{\max }}{\sigma} 2 u_{0}$. Finally, introducing the condition (28) in the above expression, gives the following lower bound on $I$ :

$$
I \geq \frac{1}{\sigma} \int_{0}^{t}\left(\frac{\lambda}{\sigma} \mu_{C}-|a|\right) y^{2}-\beta_{0} \geq \rho \int_{0}^{t} y^{2}-\beta_{0}
$$

which proves the lemma.

Remark 1: The condition (28) exhibits several interesting practical features; it relates the design parameters $(\sigma, \lambda)$ as a function of physical drillstring system characteristics such as the nominal $W_{o B}\left(u_{0}\right)$, the rock friction features $\left(\mu_{S}-\mu_{C}\right)$, and the desired rotational velocity $\left(\omega_{d}\right)$. The parameter $\rho$ as shown latter, provides a measure of the convergence rate of the output $y$ to zero.

We are now in position to establish the main stability result.

Theorem 1: Consider the closed-loop system of Figure 5 with $G(s), \Gamma^{*}, \Delta^{*}$ holding the following properties:

(i) $G(s)$ is a PR operator satisfying (18)-(19)

(ii) $\Delta^{*}$ is a passive map satisfying (26) 
(iii) $\Gamma^{*}$ is a strictly input passive map satisfying (29), i.e. design parameters are such that the condition (28) holds.

Then, $\left(e^{*}, \tilde{u}^{*}\right)=(0,0)$ is a globally asymptotically stable equilibrium of the considered closed-loop system.

Proof: Let us take the following scalar function:

$$
\begin{aligned}
V(e, \tilde{u})= & \frac{1}{2} e^{T} P e+\int_{0}^{t} y\left(\tilde{u}_{2}+\varepsilon y\right)+ \\
& +\left[I(\tilde{u}, y)+\beta_{0}-\rho \int_{0}^{t} y^{2}\right]
\end{aligned}
$$

From (26) and (29), we have that $V(e, \tilde{u})$ is semi-positive definite.

Computing the time-derivative of $V(e, \tilde{u})$, and using the properties $(i)-($ iii $)$ of the theorem, results in:

$$
\dot{V}(e, \tilde{u})=-\frac{1}{2} e^{T} L^{T} L e-\rho y^{2} \leq 0, \forall e, \tilde{u}
$$

Therefore, from last Equation, we have that $y \rightarrow 0$ with a rate depending on the value of $\rho$. The rest of the proof follows from the application of the LaSalle's invariance principle. From Equation (10), we can see that if $y \rightarrow 0$, together with the fact that $\sigma$ is a positive constant and $\Phi(0)=0$, gives that $\tilde{u} \rightarrow 0$. Finally, this implies that the two last terms in Equation (9) also tends to zero, i.e.

$$
\lim _{t \rightarrow \infty}\left[\mu(y) \tilde{u}+\tilde{\mu}(y) u_{0}\right]=\left[\mu(0) 0+\tilde{\mu}(0) u_{0}\right]=0
$$

since $\mu(0)=\mu^{*}=\mu_{C}$, and $\tilde{\mu}(0)=\mu(0)-\mu^{*}=\mu^{*}-\mu^{*}=0$. Therefore, this results in

$$
\dot{e}=A_{c l} e+H_{c l} \lim _{t \rightarrow \infty}[\cdot]=A_{c l} e
$$

So it can be concluded that $e \rightarrow 0$, and hence that $e^{*}=0$, and $\tilde{u}^{*}=0$ are a globally asymptotically stable equilibria.

\section{Simulation EXAMPLE}

In order to demonstrate the behavior of the proposed adaptive law, simulations of the drillstring system controlled under the D-OSKIL mechanism designed in Section III are shown in Figures 7 and 8 . The values ${ }^{2}$ for system model parameters used in the simulations are presented in Table I. In these Figures, the typical profiles in terms on rotatory velocity, both in surface and downhole, and system $W_{o B}$ are shown.

As it can be observed, with the nominal weight $u_{0}=40000 N$, the system is under a sustained oscillation regime. The D-OSKIL mechanism is activated at $t=50 \mathrm{~s}$, and in both cases, the controller is able to extinguish such oscillations, although the $W o B$ profiles obtained are quite different. In the two simulations, the stabilization time for the value of $W_{O B}$ is similar, and thus the range of variation obtained in the $W o B$.

On the other hand, in Figure 8 (with control parameters $\lambda=4 \cdot 10^{4}$ and $\sigma=5$ ), the $W_{o B}$ response is much smoother

\footnotetext{
${ }^{2}$ The numerical values of the drilling system parameters according to a $2000 \mathrm{~m}$ long drillstring have been taken from [16].
}

than the one obtained in Figure 7 (with control parameters $\lambda=6.6 \cdot 10^{3}$ and $\sigma=1$ ). However, the transition from oscillation regime to stabilization period is faster in Figure 8.

This issue is due to the $\lambda$ value, since the bigger value of $\lambda$ is chosen, the sharper $W_{o B}$ value transition is obtained in the switching instant of time (in our simulations $t=50 \mathrm{~s}$ ).

From the practical point of view and in order to avoid oscillations in the control signal, the parameters values proposed in Figure 8 seems to be more proper.

TABLE I

PARAMETER VAlues USED IN SIMULATION OF FIGU
\begin{tabular}{|c|r|c|}
\hline Parameter & Value & Unit \\
\hline$J_{r}$ & 2122 & {$\left[\mathrm{Kg} \cdot \mathrm{m}^{2}\right]$} \\
$J_{b}$ & 374 & {$\left[\mathrm{Kg} \cdot \mathrm{m}^{2}\right]$} \\
$k$ & 473 & {$[\mathrm{Nm} / \mathrm{rad}]$} \\
$c$ & 23.2 & {$\left[1 / \mathrm{s}^{2}\right]$} \\
$d_{r}$ & 425 & {$[1 / \mathrm{s}]$} \\
$d_{b}$ & 50 & {$[1 / \mathrm{s}]$} \\
$\mu_{C}$ & 0.3 & {$[-]$} \\
$\mu_{S}$ & 0.35 & {$[-]$} \\
$v_{s}$ & 0.01 & {$[\mathrm{rad} / \mathrm{s}]$} \\
$u_{0}$ & 40000 & {$\left[\mathrm{Kg} \cdot \mathrm{m} / \mathrm{s}^{2}\right]$} \\
$\omega_{d}$ & 5 & {$[\mathrm{rad} / \mathrm{s}]$} \\
$k_{1}$ & 15725 & {$[\mathrm{Nm} / \mathrm{rad} / \mathrm{s}]$} \\
$k_{2}$ & 30576 & {$[\mathrm{Nm} / \mathrm{rad}]$} \\
$k_{3}$ & 194 & {$[\mathrm{Nm} / \mathrm{rad} / \mathrm{s}]$} \\
\hline
\end{tabular}
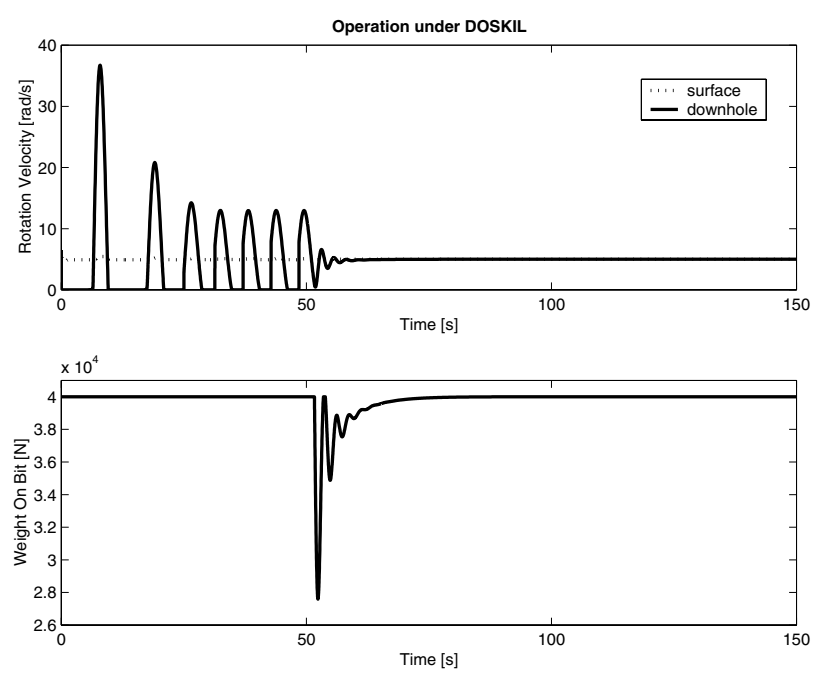

Fig. 7. Simulation of D-OSKIL scheme with $\sigma=1$ and $\lambda=6.6 \cdot 10^{3}$.

\section{Conclusions}

In this paper, we have presented a stability analysis of a variant of the D-OSKIL control mechanism, introduced in [3], to remove stick-slip oscillations in drillstring systems. The presented stability analysis based on passivity has shown that this algorithm is globally asymptotically stable. Simulations applying such an algorithm showed that stickslip oscillations can be effectively eliminated.

The implementation of the proposed control algorithm requires the sign of a friction torque on the bit, $\mu(y)$, which can be computed if the sign of rotational velocity measured at the bit is known. Therefore, the measurement of this velocity 

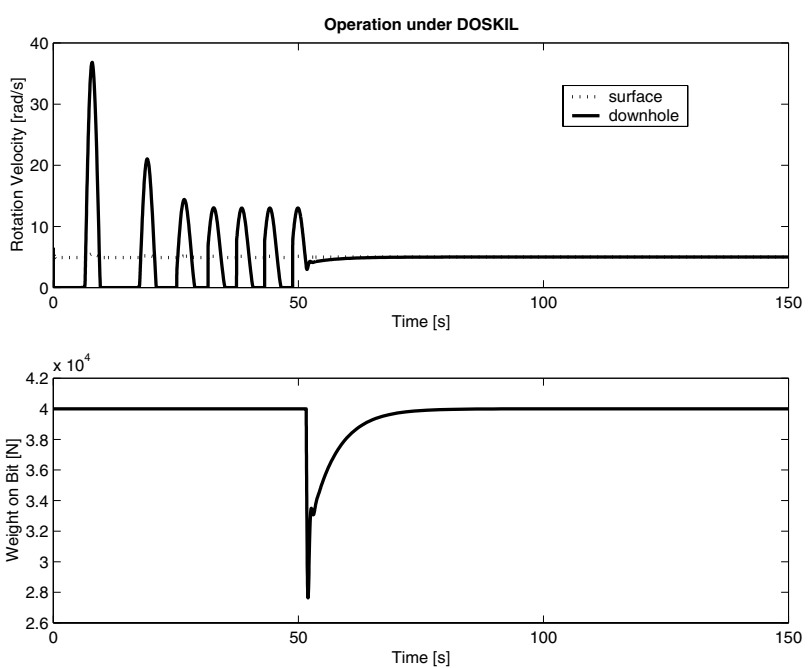

Fig. 8. Simulation of D-OSKIL scheme with $\sigma=5$ and $\lambda=4 \cdot 10^{4}$.

is necessary, but this limitation can be undertaken by the proper design of an observer. A construction of a scaled drillstring platform to carry in-house laboratory experiments is under development.

\section{ACKNOWLEDGMENTS}

The authors would like to acknowledge MCYT-FEDER for funding this work under grants DPI2004-06419, HF20030237 and SAB2003-0085. Thanks for funding are also due to the programm PICASSO No. 07261YJ(EGIDE), of the French Minister of foreign affaires.

\section{REFERENCES}

[1] Abbasssian, F., Dunayevsky, V.A. Application of Stability Approach to Torsional and Lateral Bit Dynamics. SPE Drilling and Completion, 13(2):99-107, 1998.

[2] Al-Harthi, M.E., Yaz, E. Reduced Order PI Compensator for Disturbance Suppression in Oil Well Drillstrings. Proceedings of the 2002 International Conference of Control Applications, 559-563, 2002.

[3] Canudas-de-Wit, C., Corchero, M.A., Rubio, F.R., Navarro-Lopez, E.M. D-OSKIL: A new mechanism for suppressing stick-slip in oil well drillstrings. CDC-ECC'05, Seville (Spain), 2005.

[4] Christoforou, A. P., Yigit, A. S. Fully coupled vibrations of actively controlled drilstrings. Journal of Sound and Vibration, 267:1029-1045, 2003.

[5] Defourny, P.M., Abbassian, F. Flexible Bit: a New Antivibration PDCbit Concept. SPE Drilling and Completion, 13:237-242, 1998.

[6] Harris, C.M., Piersol, A.G. Harris's Shock and Vibration Handbook. McGraw-Hill, 5th edition, 2002.

[7] Jansen, J. D., van den Steen, L. Active Damping of Self-excited Torsional Vibrations in Oil Well Drillstrings. Journal of Sound and Vibration, 179(4):647-668, 1995.

[8] Khalil, H.K. Nonlinear Systems. Prentice-Hall, 2nd edition, 1996.

[9] Kyllingstad, A., Halsey, G. W. A Study of Slip/stick Motion of the Bit. SPE Drilling Engineering, pages 369-373, 1988.

[10] Navarro-Lopez, E.M. Notas acerca del modelado, analisis y control de las vibraciones mecanicas en una sarta de perforacion. Instituto Mexicano de Petroleo, programa de investigación en matematicas aplicadas y computacion edition, 2003.

[11] Navarro-Lopez, E.M. and Suarez-Cortez, R. Practical approach to modelling and controlling stick-slip oscillations in oilwell drillstrings. IEEE International Conference on Control Applications, pages 14541460, 2004.

[12] Navarro-Lopez, E.M. and Suarez-Cortez, R. Vibraciones mecánicas en una sarta de perforación: problemas de control. Revista Iberoamerica de Automática e Informática Industrial, 2(1), 2005.
[13] Pavone D. R., Desplans J.P. Application of High Sampling Rate Downhole Measurements for Analysis and Cure of Stick-slip in Drilling. in SPE Annual Technical Conference and Exhibition, SPE 28324:335-345, 1994.

[14] Salman, M., El Raggal, H. Rotatory Drilling the Khuff Formation with PDC Bits. Journal of Petroleum Technology, Bit Technology, December:38, 1999.

[15] Sananikone, P., Kamoshima, O., White, D.B. A Field Method for Controlling Drillstring Torsional Vibrations. in IADC/SPE Drilling Conference, IADC/SPE 23891:443-452, 1992.

[16] Serrarens A.F.A, van de Molengraft M.J.G., Kok J.J. and van den Steen L. $H_{\infty}$ control for suppressing stick-slip in oil well drillstrings. IEEE Control Systems Magazine, 18(2), 1998.

[17] Spanos, P.D., Chavallier, A.M., Politis N.P. and Payne M.L. Oil well drilling: A vibrations perspective. The Shock and Vibration Digest, 35(2):81-99, 2003.

[18] Vidyasagar, M. Nonlinear Systems Analysis. Prentice-Hall, second edition, 1993. 